\title{
In Vitro Sustained Release Study of Gallic Acid Coated with Magnetite-PEG and Magnetite-PVA for Drug Delivery System
}

\author{
Dena Dorniani, ${ }^{1}$ Aminu Umar Kura, ${ }^{2}$ Samer Hasan Hussein-Al-Ali, ${ }^{3}$ \\ Mohd Zobir Bin Hussein, ${ }^{1}$ Sharida Fakurazi, ${ }^{2}$ Abdul Halim Shaari, ${ }^{4}$ and Zalinah Ahmad ${ }^{2,5}$ \\ ${ }^{1}$ Materials Synthesis and Characterization Laboratory (MSCL), Institute of Advanced Technology (ITMA), \\ Universiti Putra Malaysia, 43400, Selangor, Malaysia \\ ${ }^{2}$ Vaccines and Immunotherapeutics Laboratory (IBS), Universiti Putra Malaysia, 43400, Selangor, Malaysia \\ ${ }^{3}$ Laboratory of Molecular Biomedicine, Institute of Bioscience, Universiti Putra Malaysia, 43400, Selangor, Malaysia \\ ${ }^{4}$ Physics Department, Faculty of Science, Universiti Putra Malaysia, 43400, Selangor, Malaysia \\ ${ }^{5}$ Chemical Pathology Unit, Department of Pathology, Faculty of Medicine and Health Sciences, Universiti Putra Malaysia, \\ 43400, Selangor, Malaysia
}

Correspondence should be addressed to Mohd Zobir Bin Hussein; mzobir@upm.edu.my

Received 2 December 2013; Accepted 5 January 2014; Published 5 March 2014

Academic Editors: D. A. Ferrer and Y. Huang

Copyright (C) 2014 Dena Dorniani et al. This is an open access article distributed under the Creative Commons Attribution License, which permits unrestricted use, distribution, and reproduction in any medium, provided the original work is properly cited.

\begin{abstract}
The efficacy of two nanocarriers polyethylene glycol and polyvinyl alcohol magnetic nanoparticles coated with gallic acid (GA) was accomplished via X-ray diffraction, infrared spectroscopy, magnetic measurements, thermal analysis, and TEM. X-ray diffraction and TEM results showed that $\mathrm{Fe}_{3} \mathrm{O}_{4}$ nanoparticles were pure iron oxide having spherical shape with the average diameter of $9 \mathrm{~nm}$, compared with $31 \mathrm{~nm}$ and $35 \mathrm{~nm}$ after coating with polyethylene glycol-GA (FPEGG) and polyvinyl alcoholGA (FPVAG), respectively. Thermogravimetric analyses proved that after coating the thermal stability was markedly enhanced. Magnetic measurements and Fourier transform infrared (FTIR) revealed that superparamagnetic iron oxide nanoparticles could be successfully coated with two polymers (PEG and PVA) and gallic acid as an active drug. Release behavior of gallic acid from two nanocomposites showed that FPEGG and FPVAG nanocomposites were found to be sustained and governed by pseudo-secondorder kinetics. Anticancer activity of the two nanocomposites shows that the FPEGG demonstrated higher anticancer effect on the breast cancer cell lines in almost all concentrations tested compared to FPVAG.
\end{abstract}

\section{Introduction}

Recently, nanoparticles are attracting considerable attention in biomedical applications due to their superior physical and chemical properties. In biomedical applications which required core-shell magnetic nanoparticles, a metal or metallic oxide core, encapsulated in a polymeric coating, resulted in stable, biocompatible, and biodegradable nanoparticles. For superparamagnetic iron oxide nanoparticles, $\mathrm{Fe}$ is being reused/recycled by cells using normal biochemical pathways for the Fe metabolism [1-3]. In drug delivery system, superparamagnetism is essential because, whenever the external magnetic field [4] is removed, magnetization disappears, and therefore agglomeration in capillary vessels can be avoided [5].
If the Fe-based magnetic materials consisting of very small crystallites, saturation magnetization is found to decrease sharply which is related to crystalline magnetic anisotropy constant and nanoparticles become superparamagnetic at sizes $<25 \mathrm{~nm}[2,6,7]$. Polymeric nanoparticles have superior ability to target drugs and reducing toxic side effects on healthy cells and tissues. Polymeric nanoparticles are colloidal solid with spherical, branched, or shell structures with various sizes ranging from 10 to $1000 \mathrm{~nm}$ [8]. Due to the coating of nanoparticles with a neutral and hydrophilic compound such as polyethylene glycol (PEG) $[9,10]$, polyvinyl alcohol (PVA) [11, 12], polysaccharides [13], and dysopsonins (HSA), the circulatory half-life can be increased from minutes to hours or days. Polyvinyl alcohol (PVA) is a hydrophilic 
polymer with a simple chemical structure: high hydroxyl group which is suitable for biomedical applications due to desired many properties such as biocompatibility, nontoxicity, noncarcinogenicity, nonimmunogenicity, and inertness in body fluids. Due to promising biomaterial properties, several studies have focused on the application of PVA in biomedical and pharmaceutical fields.

Drugs can be adsorbed, dissolved, entrapped, attached, or encapsulated into the nanoparticles matrix and resulted in the nanoparticles with sustained release of drugs over longer time periods [8, 14]. Gallic acid (3,4,5-trihydroxybenzoic acid), an anticancer drug, can be obtained from a variety of natural products such as gallnut, sumac, and black tea [15-17]. Apart from anticarcinogenic properties it also has antimutagenic, antiviral, anti-inflammatory, and antimicrobial agent properties $[15,17-19]$.

This study concerns the comparing of the immobilization of gallate anion on the surface of magnetite nanoparticles preprepared using polyethylene glycol (PEG) and polyvinyl alcohol (PVA) as a polymer stabilizer, to improve the reducing of the size distribution of the nanoparticles and active delivery to specific cells targeting in normal human fibroblasts (3T3) and in several cancer cell lines. In this study, magnetite was chosen as a core and gallate anion-PVA or PEG was chosen as shells to be adsorbed on the surface of the core. In this paper, results from the XRD, FTIR, magnetite studies, TGA/DTG, particle size analysis, and cytotoxicity as well as release property of gallate anion from both nanocomposites into aqueous media will be discussed.

\section{Materials and Methods}

2.1. Materials. Distilled deionized water $\left(18.2 \mathrm{M} \cdot \Omega \mathrm{cm}^{-1}\right)$ was used in all experiments. Iron (II) chloride tetrahydrate $\left(\mathrm{FeCl}_{2} \cdot 4 \mathrm{H}_{2} \mathrm{O} \geq 99 \%\right)$, iron (III) chloride hexahydrate $\left(\mathrm{FeCl}_{3}\right.$. $6 \mathrm{H}_{2} \mathrm{O}, 99 \%$ ), and polyvinyl alcohol (98\% degree of hydrolysis) were purchased from Merck, Germany. Polyethylene glycol, average M.W. 300, was purchased as a raw material from Acros Organics BVBA. Ammonia solution (25\%) was obtained from Scharlau, and gallic acid with $97 \%$ purity was supplied by Sigma-Aldrich (St. Louis, MO).

\subsection{Preparation of Magnetite Nanoparticles. Iron oxide nano-} particles were prepared as previously reported by Lee et al. [20]. In order to prepare magnetite iron oxide coated with polyethylene glycol and gallic acid (FPEGG), the mixture of $2.43 \mathrm{~g}$ ferrous chloride tetrahydrate $\left(\mathrm{FeCl}_{2} \cdot 4 \mathrm{H}_{2} \mathrm{O}\right), 0.99 \mathrm{~g}$ ferric chloride hexahydrate $\left(\mathrm{FeCl}_{3} \cdot 6 \mathrm{H}_{2} \mathrm{O}\right)$, and $80 \mathrm{~mL}$ deionized water in the presence of $6 \mathrm{~mL}$ ammonia hydroxide $(25 \%$ by mass) was exposed to ultrasonic irradiation for $1 \mathrm{~h}$. The precipitates were centrifuged and washed 3 times and then the washed precipitates were dispersed in $100 \mathrm{~mL}$ deionized water and mixed with 1\% PEG. After stirring the mixture for 24 hours, the black precipitates were collected by a permanent magnet and washed three times to remove the excess PEG which does not participate in the coating process and then dried in an oven. The $2 \%$ of drug, GA $[4,21]$ which was dissolved in deionized water, was added into the magnetitePEG and the mixture was stirred for $24 \mathrm{~h}$. Finally, the coated magnetite was washed and dried in an oven. The same procedure was done to prepare magnetite iron oxide coated with polyvinyl alcohol-gallic acid.

\section{Cell Viability Study}

3.1. Cell Culture. Normal lung's cells and breast cancer cell lines were obtained from the American Tissue Culture Collection (VA, USA); DMEM/F12 (Dulbecco's modified essential medium/Ham's 12 nutrient mixture, Gibco), supplemented with $10 \%(\mathrm{v} / \mathrm{v})$ foetal bovine serum (JS Bioscience, Australia), and $1 \%(\mathrm{v} / \mathrm{v})$ antibiotic $(2 \mathrm{mML}$ glutamine, $100 \mathrm{U} / \mathrm{mL}$ penicillin, and $0.1 \mathrm{mg} / \mathrm{mL}$ streptomycin; Gibco) were used to culture the cell lines. A temperature controlled $\left(37^{\circ} \mathrm{C}\right)$ and $5 \%$ humidified $\mathrm{CO}_{2}$ incubator was used to keep the cells. Enzymatically detached cells (trypsin) after confluence were resuspended in new media and seeded in a 96-well plate for treatment and onward viability assays and in both cell lines $90 \%$ confluence was used before seeding.

3.2. Preparation of FNPs, FPEGG, and FPVAG Nanocomposites for Viability Assay. Experiments were done in triplicate and each time freshly prepared FNPs and both nanocomposites (FPEGG and FPVAG) were used to treat cells. In order to ensure the uniform suspension, stock suspensions of $10 \mathrm{mg} / \mathrm{mL}$ of each nanocomposites and FNPs were made by sonication for 30 minutes and culture medium was used to obtain the desired concentration via serial dilution. The nanoparticles coated with gallic acid-PVA (FPVAG) and gallic acid-PEG (FPEGG) as well as the corresponding iron oxide nanoparticles (FNPs) without any coating were initially dispersed into the phosphate buffered solution. To further disperse the FNPs and both nanocomposites, vortex agitation for $2 \mathrm{~min}$ was used prior to treatment. Dose range of $0.78 \mu \mathrm{g} / \mathrm{mL}$ to $25.00 \mu \mathrm{g} / \mathrm{mL}$ was used, and cells were exposed for $72 \mathrm{hr}$ to assess the impact of the treatment on the cells viability; wells containing cells and media only were used as control for comparison.

3.3. Cytotoxicity Testing. Cytotoxicity testing was performed using MTT assay. Principally only viable cells through their mitochondrial dehydrogenase enzymes reduce the tetrazolium salt to form a blue formazan product [22]. Cells were seeded in 96-well plates (Nunc, Denmark) at a density of $1 * 10^{5}$ cells $/ \mathrm{mL}$ in $100 \mu \mathrm{L}$ medium containing $10 \%$ FBS. The principle of this assay is by reduction of the tetrazolium salt by the mitochondrial dehydrogenase of only viable cells, which forms a blue formazan product. Twenty-four-hour period was chosen to allow cells to adhere in the 96-well plates and cells were treated with the selected increasing concentrations of each nanomaterial prepared as well as pure gallic acid. Control and test exposure media were removed after $72 \mathrm{hr}$ of exposure and each well was rinsed with PBS. To each well $100 \mu \mathrm{L}$ of new media containing $10 \%$ MTT solution was added and incubated in an incubator for $4 \mathrm{hr}$ allowing yellow formazan formation by the viable cells (MTT solution is 
made as $5 \mathrm{mg} / \mathrm{mL}$ PBS). After the $4 \mathrm{hr}$ incubation period, the medium was discarded, the cells were washed with $100 \mu \mathrm{L}$ of PBS, and $100 \mu \mathrm{L}$ of DMSO was added to each well to extract the dye. Absorbance was measured at $570 \mathrm{~nm}$ and a background absorbance was measured at $630 \mathrm{~nm}$. Then cytotoxicity was calculated as Average of treated/Average of control $* 100 \%$.

3.4. Controlled-Release Procedure. In order to evaluate the drug release profiles of gallic acid from FPEGG and FPVAG, two $\mathrm{pH}$ values (7.4 and 4.8 ) were used at $25^{\circ} \mathrm{C}$ [23-26]. The release of GA was achieved by adding $10 \mathrm{mg}$ of FPEGG and FPVAG nanocomposites into the mixture of $1 \mathrm{~mL} \mathrm{HCl}$ and $3 \mathrm{~mL} \mathrm{HNO}_{3}$ and marked them up to $10 \mathrm{~mL}$ by deionized water after stirring for 24 hours. Different anions such as $\mathrm{Cl}^{-}, \mathrm{HPO}_{4}{ }^{2-}$, and $\mathrm{H}_{2} \mathrm{PO}_{4}{ }^{-}$were used in this study. Using ultraviolet-visible spectroscopy, the accumulated amount of GA released from FPEGG and FPVAG nanocomposites was measured at $\lambda_{\max }=264 \mathrm{~nm}$.

3.5. Characterization. Powder X-ray diffraction (PXRD) was recorded using a Shimadzu diffractometer XRD-6000 (Tokyo, Japan) instrument to determine the crystal structure of the samples in a range of $6-70^{\circ}$ using $\mathrm{CuK}_{\alpha}$ radiation $(\lambda=$ $1.5406 \AA$ ) at $40 \mathrm{kV}$ and $30 \mathrm{~mA}$. Fourier transform infrared (FTIR) spectra of the materials were obtained over the range of $400-4000 \mathrm{~cm}^{-1}$ on a Thermo Nicolet Nexus FTIR (model smart orbit) with $4 \mathrm{~cm}^{-1}$ resolution, using a $\mathrm{KBr}$ disc method with approximately $1 \%$ of the sample in $200 \mathrm{mg}$ of spectroscopic grade potassium bromide, and the pellets were pressed at 10 tons. Thermogravimetry analysis (TGA) and differential thermogravimetry analysis (DTG) were performed using a Mettler-Toledo Instrument (Longview, WA) in $150 \mu \mathrm{L}$ alumina crucibles in the range of $20-1000^{\circ} \mathrm{C}$ at a heating rate of 10 degrees per minute. Transmission electron microscopy (TEM) was used to observe the mean particle size, size distribution, and morphology of the samples using a Hitachi H-7100 at an accelerating voltage of $100 \mathrm{kV}$ for iron oxide nanoparticles and FPEGG nanocomposite and $80 \mathrm{kV}$ for FPVAG nanocomposite. To observe the optical properties and a controlled-release study of GA from FPVAG and FPEGG nanocomposites, ultraviolet-visible spectra (Shimadzu 1650 Series, Tokyo, Japan) were used.

\section{Results and Discussion}

4.1. X-Ray Diffraction. Representative powder X-ray diffraction patterns of bare iron oxide nanoparticles, iron oxide nanoparticles coated with PVA-gallic acid (FPVAG), and iron oxide nanoparticles coated with PEG-gallic acid (FPEGG) are presented in Figure 1. The inset in Figures 1(D), 1(E), and $1(\mathrm{~F})$ shows the X-ray diffraction spectrum of pure PEG, PVA, and GA, respectively. Figure 1(D) (pure PEG) shows two main diffraction peaks with high intensity at $2 \theta=19.3^{\circ}$ and $23.5^{\circ}$. The broad peak pertaining to PVA at $2 \theta=19.5^{\circ}$ can be due to the amorphous nature of the PVA (Figure 1(E)). All nanocomposites have six characteristic peaks at $2 \theta=30.16^{\circ}$, $35.95^{\circ}, 43.34^{\circ}, 54.17^{\circ}, 57.27^{\circ}$ and $62.98^{\circ}$, which can be indexed

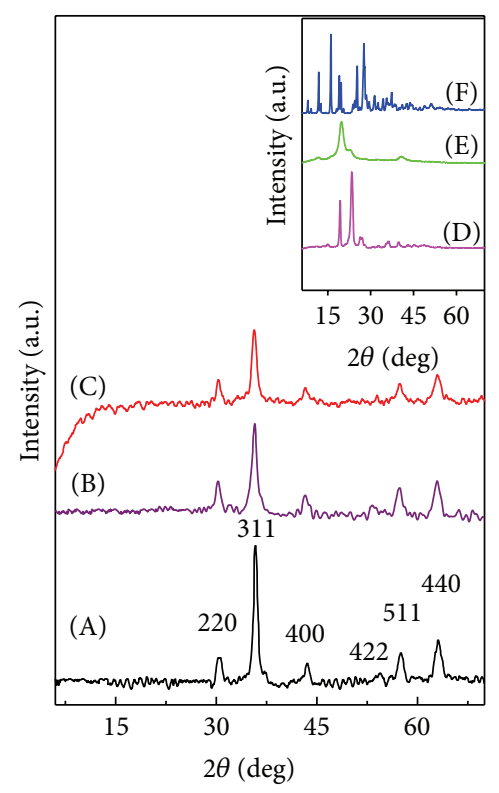

Figure 1: XRD patterns of FNPs (A), FPVAG (B), and FPEGG (C). The inset shows the XRD patterns of pure PEG (D), pure PVA (E), and pure GA (F). FPEGG: iron oxide coated with polyethylene glycol and gallic acid, FPVAG: iron oxide coated with polyvinyl alcohol and gallic acid, PEG: pure polyethylene glycol, PVA: pure polyvinyl alcohol, and GA: pure drug gallic acid.

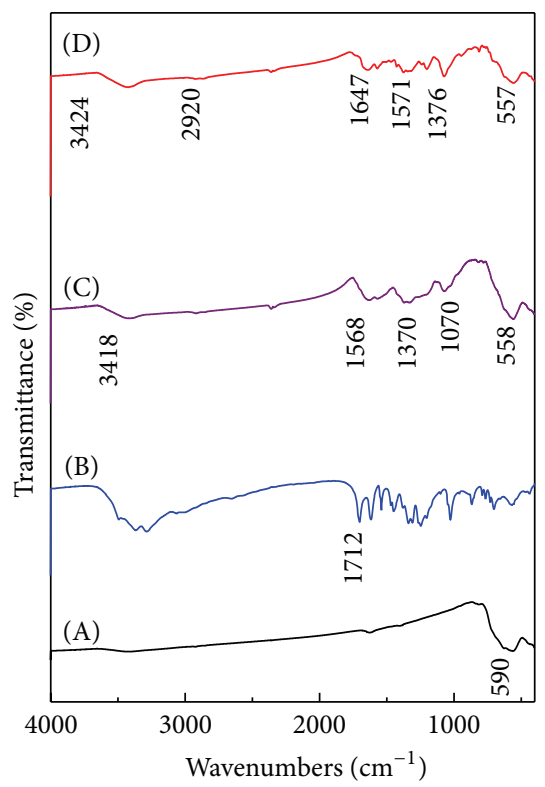

FIGURE 2: FTIR spectra of FNPs (A), pure GA (B), FPVAG (C), and FPEGG nanocomposite (D).

to the (220), (311), (400), (422), (511), and (440) Bragg reflection, respectively. From the XRD analysis, it has also been found that these six diffraction peaks correspond to the pure magnetite nanoparticles with a cubic inverse spinal structure (Reference JCPDS Number 82-1533). Because of the lack of the characteristic superlattice diffractions at (210), (213), and 


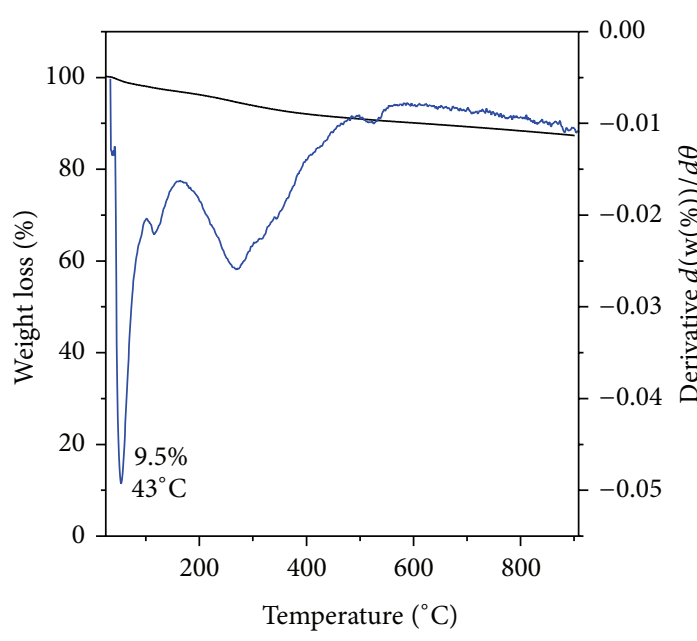

(a)

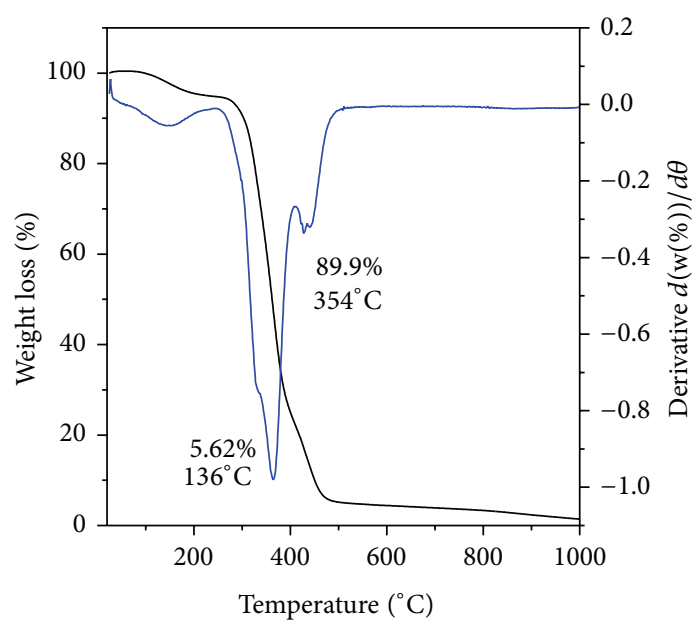

(c)

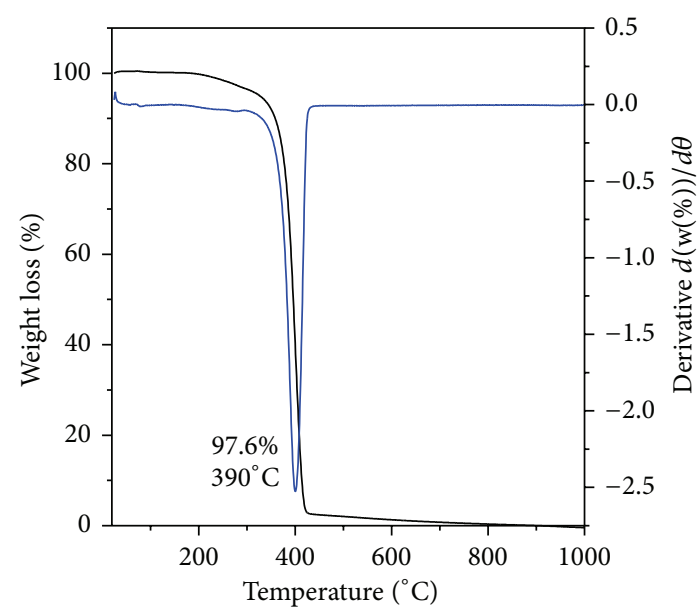

(e)

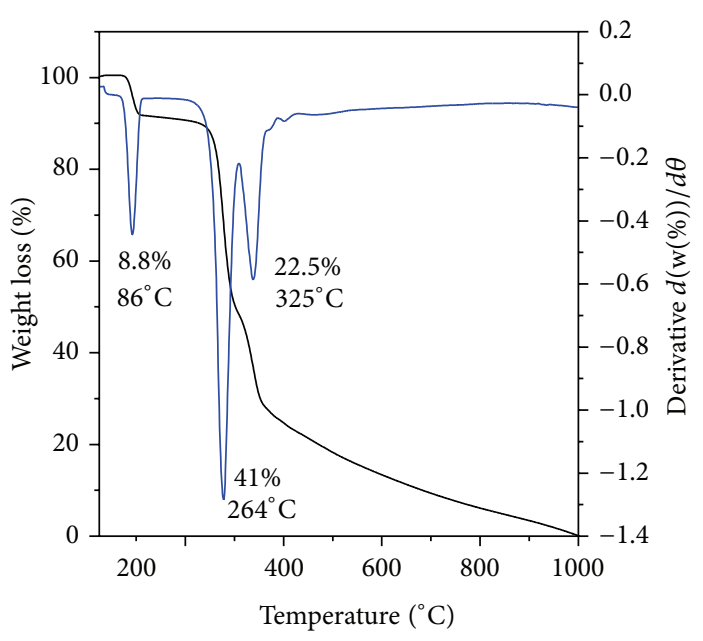

(b)

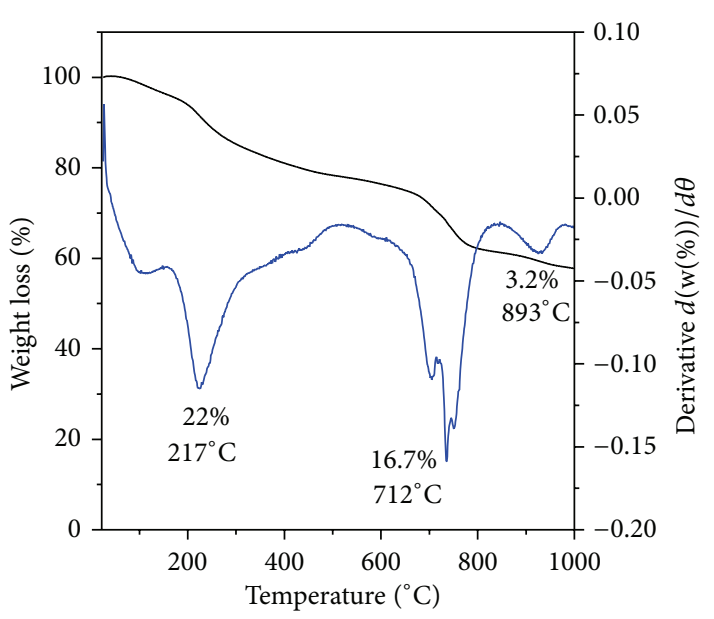

(d)

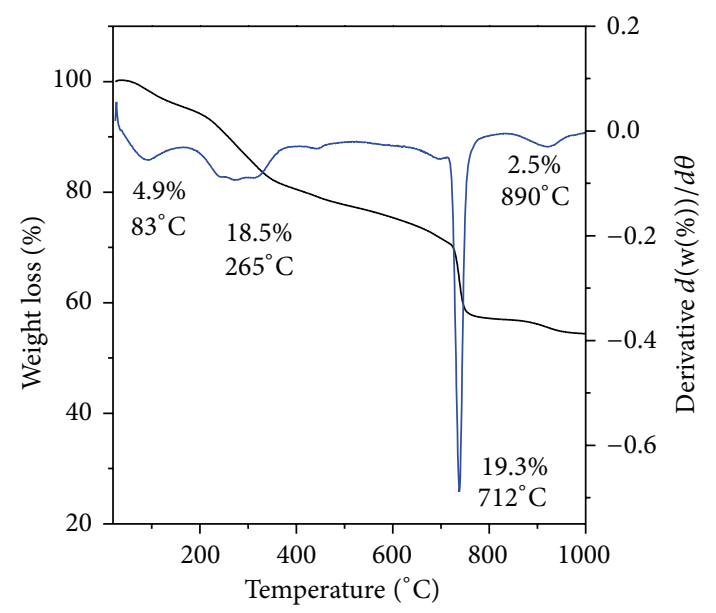

(f)

Figure 3: TGA/DTG of (a) FNPs, (b) GA, (c) PVA, (d) FPVAG nanocomposite, (e) pure PEG, and (f) FPEGG nanocomposite.

(300), it can be found that the maghemite $\left(\mathrm{Fe}_{2} \mathrm{O}_{3}, \gamma-\mathrm{Fe}_{2} \mathrm{O}_{3}\right)$ does not exist in the as-synthesized iron oxide and both nanocomposites $[27,28]$. Owing to observing these characteristic peaks in all three nanocomposites (Figures $1(\mathrm{~A})$,
$1(B)$, and $1(C))$, it is evident that the coating process did not result in a phase change of the iron oxide nanoparticles.

From the Debye-Scherrer formula $(D=K \lambda / \beta \cos \theta)$, the average crystallite size has been calculated for the bare iron 
oxide nanoparticles. The mean crystallite size of pure iron oxide nanoparticles was about $3 \mathrm{~nm}$.

4.2. Infrared Spectroscopy (FTIR). Figures 2(A)-2(D) show the FTIR spectra of FNPs, GA, FPVAG, and FPEGG, respectively. Figure 2(A) shows that the magnetite iron oxide nanoparticles (FNPs) have absorption peak at $590 \mathrm{~cm}^{-1}$, which is due to $\mathrm{Fe}-\mathrm{O}$ stretching in $\mathrm{Fe}_{3} \mathrm{O}_{4}$. However, the FPVAG and FPEGG nanocomposites show characteristic peaks of $\mathrm{Fe}-\mathrm{O}$ at 558 and $557 \mathrm{~cm}^{-1}$, respectively, which confirm the presence of magnetite nanoparticles in both nanocomposites.

In FPVAG nanocomposite (Figure 2(C)), the alcoholic $\mathrm{O}-\mathrm{H}$ stretching band was observed at $3418 \mathrm{~cm}^{-1}$. In addition, a band at $2917 \mathrm{~cm}^{-1}$ is corresponding to $\mathrm{C}-\mathrm{H}$ stretching vibration, and $1070 \mathrm{~cm}^{-1}$ is attributable to $\mathrm{M}-\mathrm{O}-\mathrm{C}(\mathrm{M}=\mathrm{Fe})$ bond [28]. This evidence confirms the attachment of PVA onto iron oxide nanoparticles via hydrogen bond between hydroxyl group of PVA and protonated surface of the oxide [28]. FTIR spectrum of the FPVAG nanocomposite shows the characteristic peaks for GA, confirming that the loaded drug on the surface of PVA is GA, for example, the peaks observed at 1568 and $1370 \mathrm{~cm}^{-1}$, which are due to asymmetry and symmetry $\mathrm{COO}^{-}$stretching, respectively.

In FPEGG nanocomposite (Figure 2(D)), the presence of hydroxyl groups formed to link PEG to the oxide surface was confirmed by the absorbance peaks for $-\mathrm{OH}$ stretching at $3424 \mathrm{~cm}^{-1}$ and $-\mathrm{OH}$ out-of-plane bending vibration at $529 \mathrm{~cm}^{-1}$ on the nanocomposite FTIR spectra [29]. In addition, the appearance of peaks at 2920 and $947 \mathrm{~cm}^{-1}$ for $-\mathrm{CH}_{2}$ stretching vibration and $-\mathrm{CH}$ out-of-plane bending vibration, respectively, confirms the presence of PEG on the nanoparticle surface [30]. FTIR spectrum of the FPEGG nanocomposite shows the characteristic peaks for GA, confirming that the drug loaded on the surface of PEG is GA. For instance, the peaks at 1462 and $1246 \mathrm{~cm}^{-1}$ are due to the $-\mathrm{OH}$ stretching [30], and the peaks observed at 1571 and $1376 \mathrm{~cm}^{-1}$ are due to asymmetry and symmetry $\mathrm{COO}^{-}$ stretching, respectively.

4.3. Thermogravimetric Analysis. The thermogravimetric and differential thermogravimetric analyses obtained for FNPs, GA, PVA, FPVAG, PEG, and FPEGG are shown in Figure 3, respectively. The TGA curves of FNPs (Figure 3(a)) show that the weight loss over the temperature range from $25^{\circ} \mathrm{C}$ to $1000^{\circ} \mathrm{C}$ was about $9.5 \%$. This might be due to the loss of residual water in the sample. For PVA polymer (Figure 3(c)), two main thermal events were clearly observed. The first event occurred in the region of $50-235^{\circ} \mathrm{C}$ with $5.6 \%$ weight loss. This was followed by the second stage at 235$509^{\circ} \mathrm{C}$, with $89.9 \%$ weight loss. Comparing the TGA curve of FNPs, PVA with FPVAG shows the curve indicating the presence of GA in the final nanocomposite. Figure 3(e) shows that PEG polymer has only one-stage weight loss, in the region of $170-433^{\circ} \mathrm{C}$ with $97.6 \%$ weight loss. The FPEGG nanocomposite shows weight loss starting from $36^{\circ} \mathrm{C}$ and completed at $961^{\circ} \mathrm{C}$ with four weight losses $\left(36-161^{\circ} \mathrm{C}, 4.9 \%\right.$;

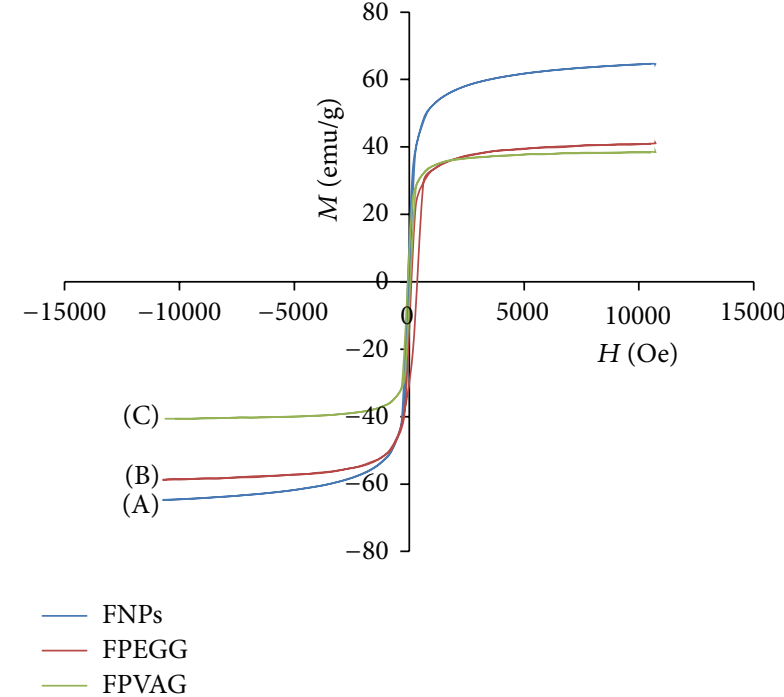

FIGURE 4: Magnetization plots of (A) FNPs, (B) FPEGG, and (C) FPVAG.

$171-543^{\circ} \mathrm{C}, 18.5 \%$; $549-793^{\circ} \mathrm{C}, 19.3 \%$; and finally $811-961^{\circ} \mathrm{C}$, $2.5 \%)$. The range of weight loss in the nanocomposite is higher than in the PEG, indicating the presence of GA in the final nanocomposite.

4.4. Magnetic Properties. Superparamagnetism is playing a key role for magnetic targeting carriers and biomedical applications and the lack of hysteresis is one of the criteria to identify the product as superparamagnetic [31]. The most important parameters in vibrating sample magnetometers (VSM) extracted from hysteresis loops are saturation magnetization (Ms), remanence magnetization $(\mathrm{Mr})$, and the coercivity $(\mathrm{Hc})$. The value of Ms (magnetization at maximum applied field) can be enhanced with the increases of crystallinity. Coercivity (Hc) is the field required for demagnetizing the sample and the low shape magnetic anisotropy can cause the lower value of Hc and Ms. Superparamagnetic materials have high saturation magnetization and zero coercivity and remanence magnetization (the magnetization at zero applied field after applying a saturation field). Figure 4 shows the hysteresis loops of naked iron oxide nanoparticles (Figure $4(\mathrm{~A})$ ), iron oxide coated with polyethylene glycolgallic acid (FPEGG) (Figure 4(B)), and iron oxide coated with polyvinyl alcohol-gallic acid (FPVAG) characterized by vibrating sample magnetometer (VSM) at room temperature. The saturation magnetization of magnetite nanoparticles synthesized by coprecipitation method was about $64.65 \mathrm{emu} / \mathrm{g}$ compared to $40.00 \mathrm{emu} / \mathrm{g}$ and $38.63 \mathrm{emu} / \mathrm{g}$ for FPEGG and FPVAG nanocomposite, respectively, which agrees nicely with previous works $[28,32,33]$. It is clear that the saturation magnetization of bare iron oxide nanoparticles depends on the method of synthesis as well as the size of the nanoparticles [34].

Therefore, the amount of saturation magnetization is usually lower than the theoretical value owing to surface inhomogeneities $[2,35,36]$. The remanence magnetization 
TABLE 1: Magnetic properties of FNPs, FPEGG, and FPVAG nanocomposites.

\begin{tabular}{lccc}
\hline Samples & $\mathrm{Ms}(\mathrm{emu} / \mathrm{g})$ & $\mathrm{Mr}(\mathrm{emu} / \mathrm{g})$ & $\mathrm{Hc}(\mathrm{G})$ \\
\hline $\mathrm{Fe}_{3} \mathrm{O}_{4}$ & 64.655 & 1.5714 & 21.955 \\
FPEGG & 40.005 & 1.1334 & 14.727 \\
FPVAG & 38.635 & 0.8359 & 24.977 \\
\hline
\end{tabular}

value for naked iron oxide was about $1.57 \mathrm{emu} / \mathrm{g}$ compared to $1.13 \mathrm{emu} / \mathrm{g}$ and $0.84 \mathrm{emu} / \mathrm{g}$ after coating with polyethylene glycol-gallic acid and polyvinyl alcohol-gallic acid, respectively. This observation also could be due to the fact that the nanoparticles which are covered were so small that they might be assumed to have a single magnetic domain [37].

Saturation magnetization of the prepared magnetic iron oxide nanoparticles, FPEGG and FPVAG nanocomposites, was high; however the remanent magnetization and coercivity $(\mathrm{Hc})$ were low. This demonstrates that all samples are soft superparamagnetic; that is, after removal of a magnetic field they did not retain any magnetism reducing the probability of particle aggregation because of magnetic dipole attraction $[38,39]$. The decrease of the saturation magnetization after coating with PEG-GA and PVA-GA is only due to the existence of coated materials on the surface of magnetite nanoparticles [40]. The values of saturation magnetization $(\mathrm{Ms})$, remanent magnetization $(\mathrm{Mr})$, and coercivity $(\mathrm{Hc})$ are shown in Table 1.

4.5. Determination of Average Particle Size and Particle Size Distribution. The typical transmission electron micrographs (TEM) and size distribution of as-prepared FNPs, FPVAG, and FPEGG nanocomposites are shown in Figure 5. The obtained images showed that the particles with nanometer size were successfully prepared by coprecipitation method and were essentially monodisperse (Figures $5(\mathrm{a}), 5(\mathrm{~b})$, and $5(\mathrm{c}))$. It was clear that FNPs and both the nanocomposites display roughly spherical shapes. The particle size and size distribution of the iron oxide nanoparticles, FPVAG and FPEGG nanocomposite, were determined by measuring around 300 particles randomly using image analysis software (a UTHSCSA Image Tool). From these images it was obvious that the particles had a very small size range between 9 and $35 \mathrm{~nm}$ in diameter with a narrow size distribution. The average diameter of the bare FNPs is $9 \pm 2 \mathrm{~nm}$, whereas after coating with PVA-GA and PEG-GA the mean size of FPVAG and FPEGG nanocomposites increased to $35 \pm 7$ and $31 \pm 4$, respectively. The results showed that there are no too many differences between the sizes of FPEGG and FPVAG nanocomposites. The enlargement of the size of FPVAG and FPEGG after coating procedure can be used to prove the formation of iron oxide nanoparticles coated with PVA-GA and PEG-GA [41].

4.6. Loading and Release Behavior of Gallic Acid. The percentages of loading of gallic acid in FPEGG and FPVAG were investigated via the ultraviolet-visible absorption spectroscopy. Loading of GA into FPVAG was found to be around 5\% compared to 7\% for the FPEGG nanocomposite. The release profiles for GA from the two mentioned nanocomposites were investigated in phosphate buffered solutions at $\mathrm{pH} 7.4$ and 4.8 (Figure 6).

The release profiles of GA from FPEGG show that the maximum percentage release reaches about $60.9 \%$ within about $6905 \mathrm{~min}(115 \mathrm{~h})$ at $\mathrm{pH} 7.4$ compared to $89.4 \%$ within about $5775 \mathrm{~min}$ when exposed to $\mathrm{pH} 4.8$ (Figure 6(a)). The inset of Figure 6(a) shows the physical mixture of GA and FNPs-PEG exposed to either $\mathrm{pH} 4.8$ or $\mathrm{pH}$ 7.4. It was found that GA was quickly released from the physical mixture of FNPs-PEG-GA and that release was complete within 2 and 4 minutes at $\mathrm{pH} 4.8$ and $\mathrm{pH} 7.4$, respectively. In addition, the release profiles of GA from FPVAG reveals that the maximum percentage release reaches about $80.9 \%$ within about $6594 \mathrm{~min}$ at $\mathrm{pH} 7.4$ compared to $86.4 \%$ within about 3045 when exposed to buffered solution at $\mathrm{pH} 4.8$ (Figure 6(b)). Also the physical mixture of GA with FNPsPVA into phosphate buffered solution at $\mathrm{pH} 4.8$ and $\mathrm{pH} 7.4$ shows the rapid release during the initial few minutes (inset of Figure 6(b)). The physical mixture of GA and both FNPsPVA and FNPs-PEG showed no sustained-release effects in both phosphate buffered solutions at $\mathrm{pH} 4.8$ and $\mathrm{pH} 7.4$ due to low electrostatic attraction between the GA anions and both FNPs-PVA and FNPs-PEG, respectively. From the results, it was found that the release profile of GA from FPEGG was more sustained compared to FPVAG nanocomposite.

4.7. Release Kinetics of Gallic Acid from the Nanocomposites FPEGG and FPVAG. The release kinetics behavior of gallic acid from FPEGG and FPVA nanocomposite could be investigated by different kinetics models such as first-order [42] $\left(\ln \left(q_{e}-q_{t}\right)=\ln q_{e}-k_{1} t\right)$, pseudo-second-order [43] $\left(t / q_{t}=\right.$ $\left.1 / k_{2} q_{e}^{2}+t / q_{e}\right)$, and parabolic diffusion [44] $\left(1-M_{t} / M_{0}\right) / t=$ $\left.k t^{-0.5}+b\right)$ equations. For the above equations, the $q_{e}$ and $q_{t}$ are the equilibrium release rate and the release rate at time $t$, respectively; $k$ is a constant corresponding to release amount; and $M_{0}$ and $M_{t}$ are the drug content remaining in FPEGG and FPVAG nanocomposites at release times 0 and $t$, respectively. On the basis of these models, mentioned earlier, it was found that the pseudo-second-order kinetic model can be better fitted to describe the release behavior of gallic acid from FPEGG and FPVAG nanocomposites compared to the other models used in this study (Figures 7(a), 7(b), 7(c), and 7(d) and Table 2).

4.8. In Vitro Bioassay. Normal lung cell and breast cancer cell lines were used to study the possible toxicity and anticancer effectiveness of the two nanocomposites as well as bare iron oxide and pure gallic acid in a dose-dependent manner. Figure 8(a) shows dose-dependent effect of iron oxide nanoparticles, FPEGG and FPVAG nanocomposites, on MCF-7 cells. It also shows the effect of these nanocomposites compared to pure gallic acid on the same cells. Statistically, there is a significant difference between the FNPs-treated group and the FPEGG-treated group with $P<$ 0.05 as tested by an ANOVA and a Turkey post hoc test. The $\mathrm{IC}_{50}$ values are $11.61 \pm 0.12 \mu \mathrm{g} / \mathrm{mL}, 16.63 \pm 0.21 \mu \mathrm{g} / \mathrm{mL}$, 

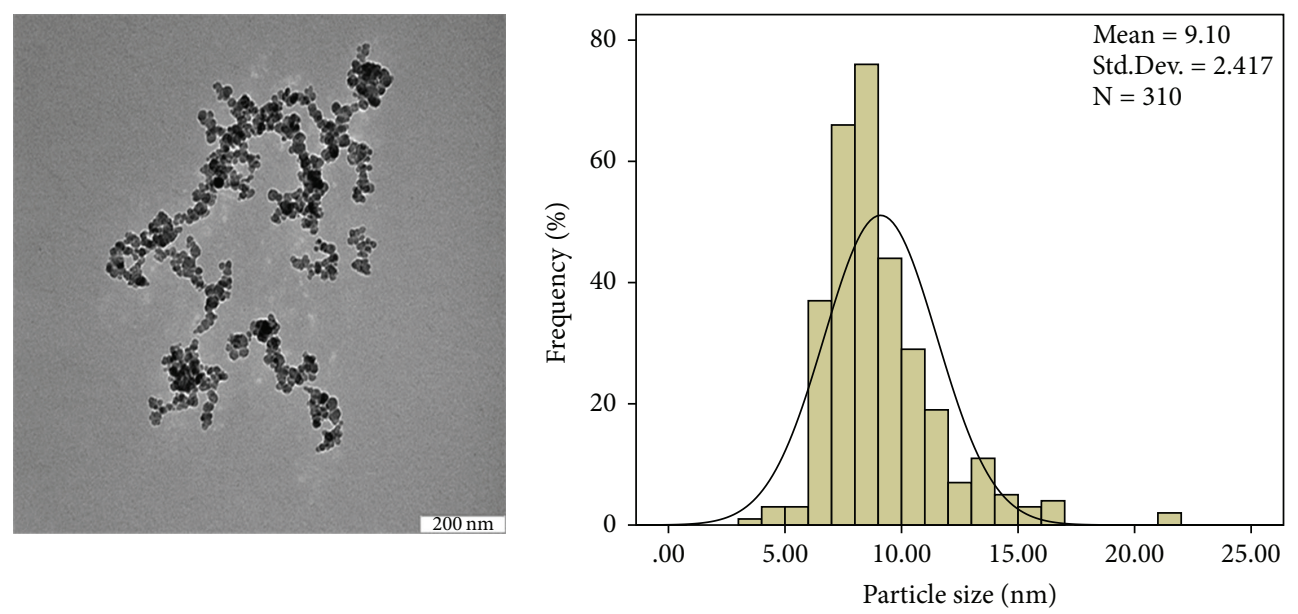

(a)
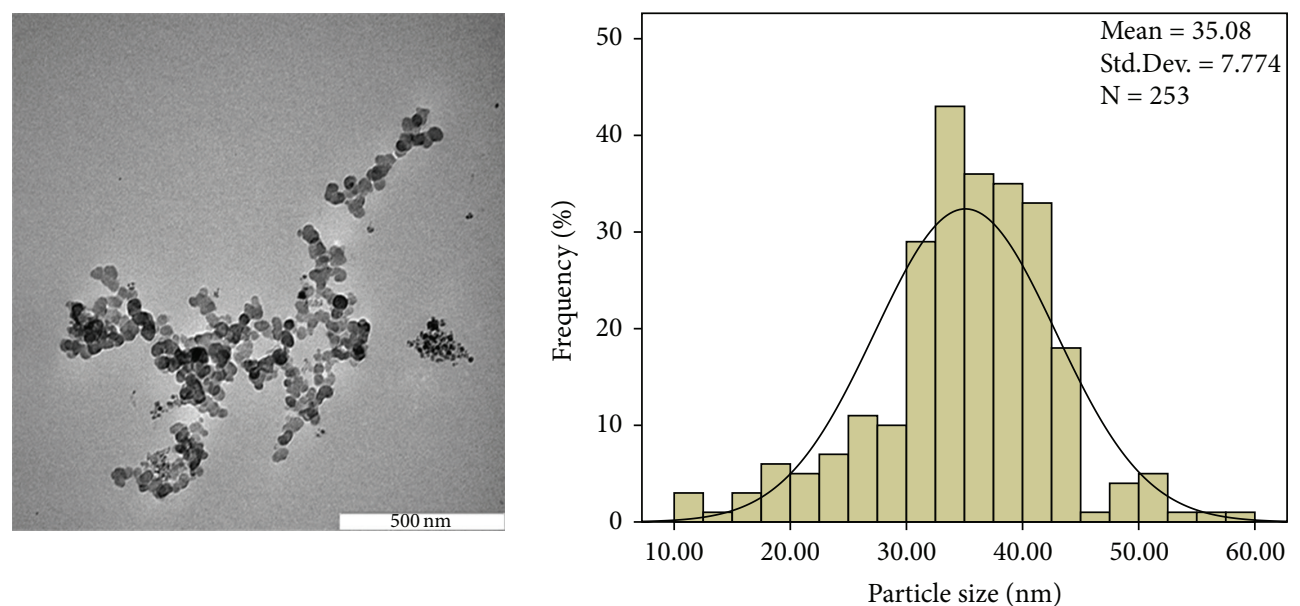

(b)
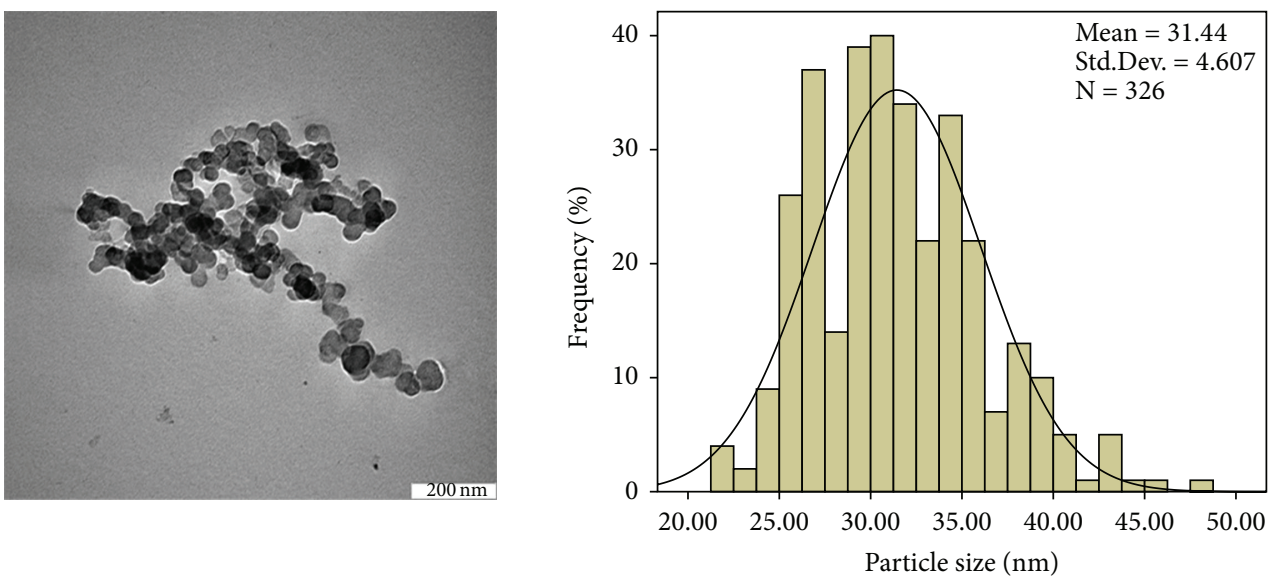

(c)

FIGURE 5: TEM micrographs of (a) FNP with $200 \mathrm{~nm}$ microbar and the particle size distribution, (b) FPVAG with $500 \mathrm{~nm}$ microbar and its particle size distribution, and (c) FPEGG nanocomposite with $200 \mathrm{~nm}$ microbar and the particle size distribution.

$18.61 \pm 0.37 \mu \mathrm{g} / \mathrm{mL}$, and $38.36 \pm 0.16 \mu \mathrm{g} / \mathrm{mL}$ for FPEGG, FPVAG, GA, and FNPs, respectively. Figure 8(b) demonstrated the viability study of MRC- 5 cells following exposure to FPEGG and FPVAG nanocomposites as compared to FNPs and pure gallic acid after $72 \mathrm{hr}$, using increasing concentrations of each compound.

The viability was found to be maintained above $80 \%$ when normal lung cells were exposed to the iron oxide 
TABLE 2: Correlation coefficient, rate constant, and half-time obtained by fitting the data of the release of GA from FPEGG and FPVAG nanocomposites into phosphate buffered solutions at $\mathrm{pH} 4.8$ and 7.4.

\begin{tabular}{|c|c|c|c|c|c|c|}
\hline \multirow{2}{*}{$\begin{array}{l}\text { Aqueous } \\
\text { solution }\end{array}$} & \multirow{2}{*}{$\begin{array}{l}\text { Saturated } \\
\text { release } \%\end{array}$} & \multicolumn{3}{|c|}{$R^{2}$} & \multirow{2}{*}{$\begin{array}{l}\text { Rate constant }(k)^{\mathrm{a}} \\
\quad(\mathrm{mg} / \mathrm{min})\end{array}$} & \multirow{2}{*}{$t_{1 / 2}{ }^{\mathrm{a}}(\min )$} \\
\hline & & Pseudo-first order & Pseudo-second order & Parabolic diffusion & & \\
\hline $\mathrm{pH} 7.4^{*}$ & 60.9 & 0.7893 & 0.9992 & 0.8651 & $6.41 \times 10^{-5}$ & 254 \\
\hline $\mathrm{pH} 4.8^{*}$ & 89.4 & 0.9168 & 0.9950 & 0.9567 & $1.92 \times 10^{-5}$ & 568 \\
\hline $\mathrm{pH} 7.4^{* *}$ & 80.9 & 0.5984 & 0.9953 & 0.9816 & $3.49 \times 10^{-5}$ & 323 \\
\hline $\mathrm{pH} 4.8^{* *}$ & 86.4 & 0.9887 & 0.9989 & 0.8220 & $8.19 \times 10^{-5}$ & 141 \\
\hline
\end{tabular}

${ }^{*}$ Estimation was done for the release of GA from FPEGG nanocomposite. ${ }^{* *}$ Estimation was done for the release of GA from FPVAG nanocomposite and a estimated using pseudo-second-order kinetics.

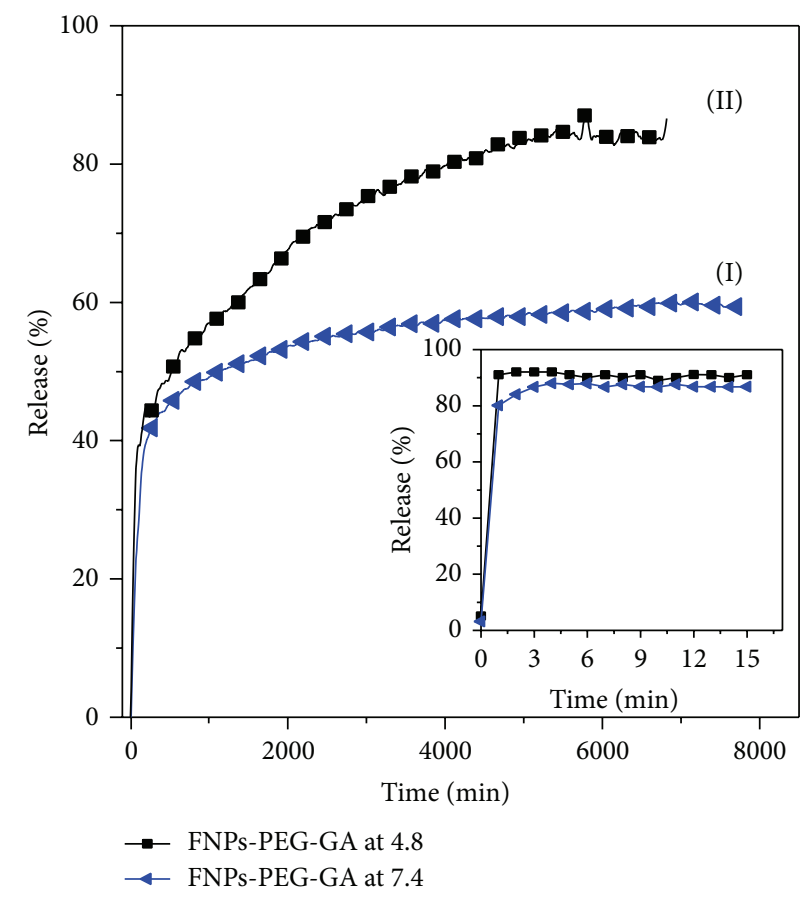

(a)

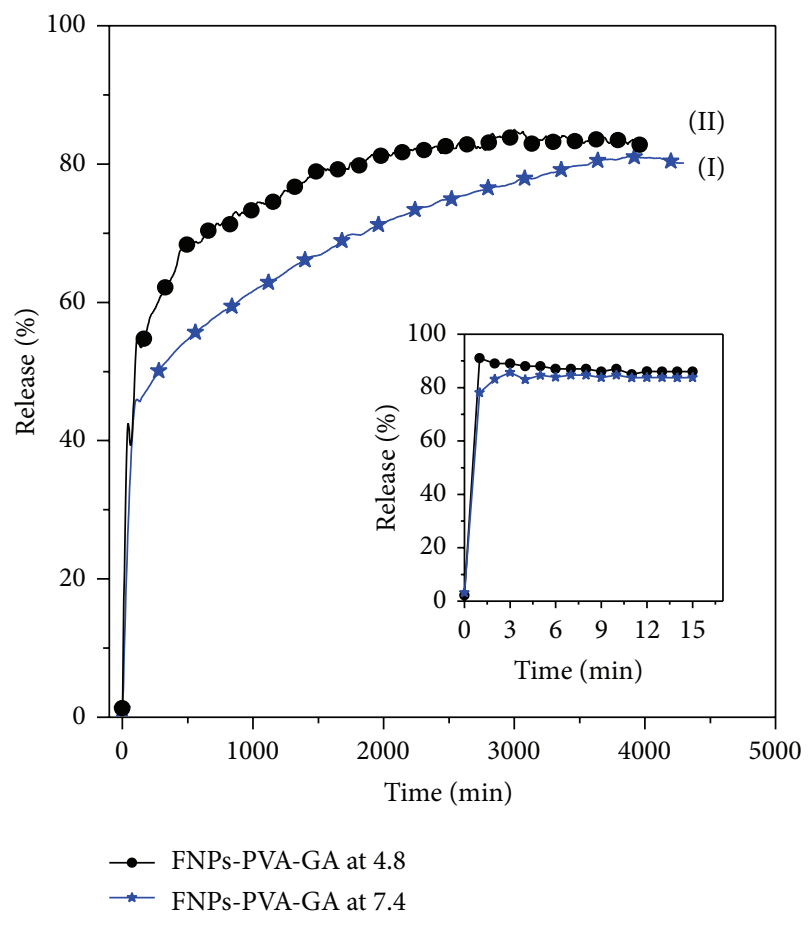

(b)

Figure 6: (a) Release profiles of GA from the FPEGG nanocomposite into (I) phosphate buffered solution at pH 7.4 and (II) phosphate buffered solution at $\mathrm{pH} 4.8$ and (b) release profiles of GA from the FPVAG nanocomposite into (I) phosphate buffered solution at pH 7.4 and (II) phosphate buffered solution at $\mathrm{pH}$ 4.8. Note: inset in (a) shows the release profiles of GA from its physical mixture of FNPs-PEG-GA at $\mathrm{pH} 7.4$ and 4.8, and inset in (b) shows the release profiles of GA from its physical mixture of FNPs-PVA-GA at pH 7.4 and 4.8.

nanoparticles, pure gallic acid, and both nanocomposites (FPEGG and FPVAG) within the tested concentrations. A dose-dependent decrease in cell viability was seen following exposure to the same concentration of the two nanocomposites and pure gallic acid on a breast cancer cell line. Figures 8(a) and 8(b) show that the sustained cell viability is above $80 \%$ when both cancer and normal cell lines were exposed to increased concentration of empty iron oxide nanoparticles over $72 \mathrm{hr}$ period. Interestingly, this indicates that the possibility of toxicity and/or anticancer effect on the cells could be due to the release of gallic acid from the nanocomposites and not owing to the empty iron oxide nanoparticles.

It was found that the FPEGG demonstrated higher anticancer effect on the breast cancer cell lines in almost all concentrations tested compared to FPVAG. There are less than $40 \%$ viable cells at $25 \mu \mathrm{g} / \mathrm{mL}$ of FPEGG, while FPVAG has about $60 \%$ viable cells and pure gallic acid about $50 \%$ viable cells at $25 \mu \mathrm{g} / \mathrm{mL}$ concentration (Figure 8(a)). Thus, in the above tested cell, FPEGG nanocomposite was found to have higher toxicity effect compared to both FPVAG and pure gallic acid. The uptake and retention of the nanoparticle is likely enhanced with a PEG coating than the PVA. This leads to different viability of the cancer cell when the same concentration of gallic acid in both FPEGG and FPVAG nanocomposites were used in this study. Previous study showed that the nanoparticles coated with vitamin $\mathrm{E}$ succinated polyethylene glycol 1000 (TPGS) were shown to have 1.4-fold increase in uptake compared to PVA coated nanoparticles [45]. 


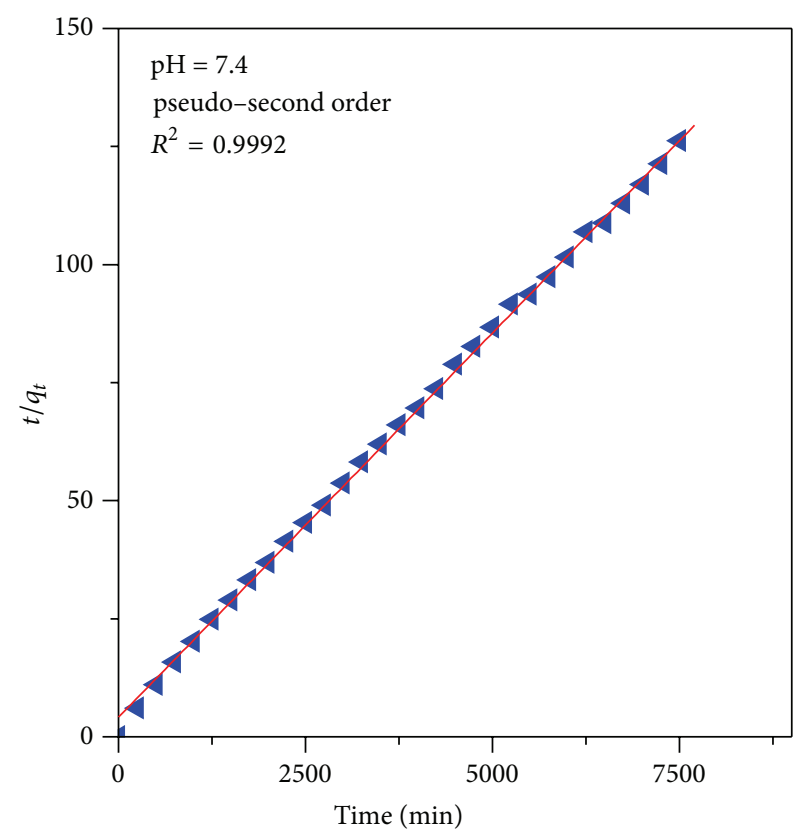

(a)

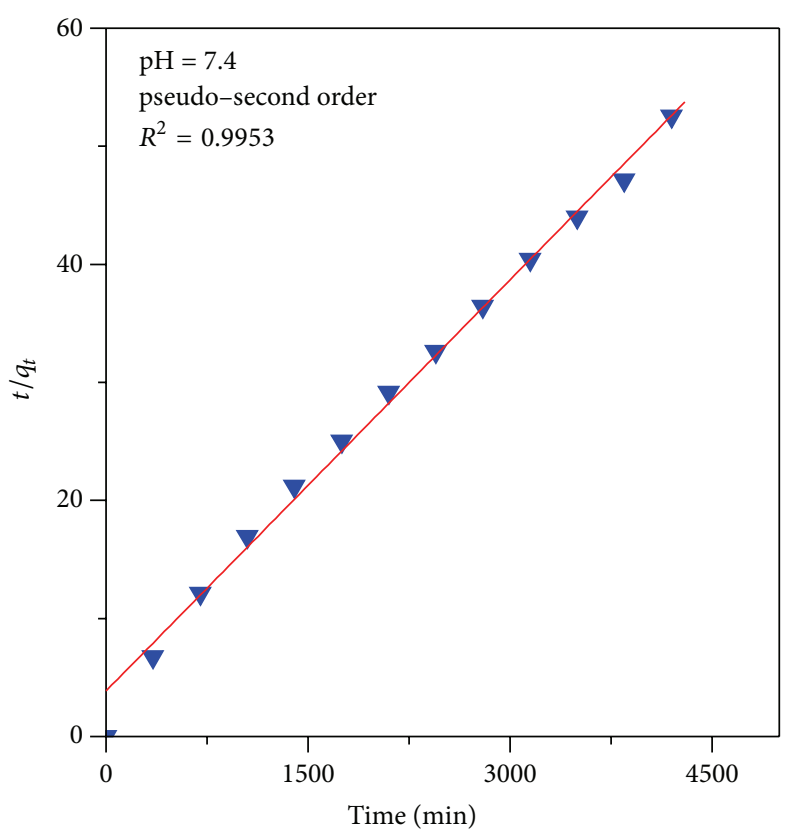

(c)

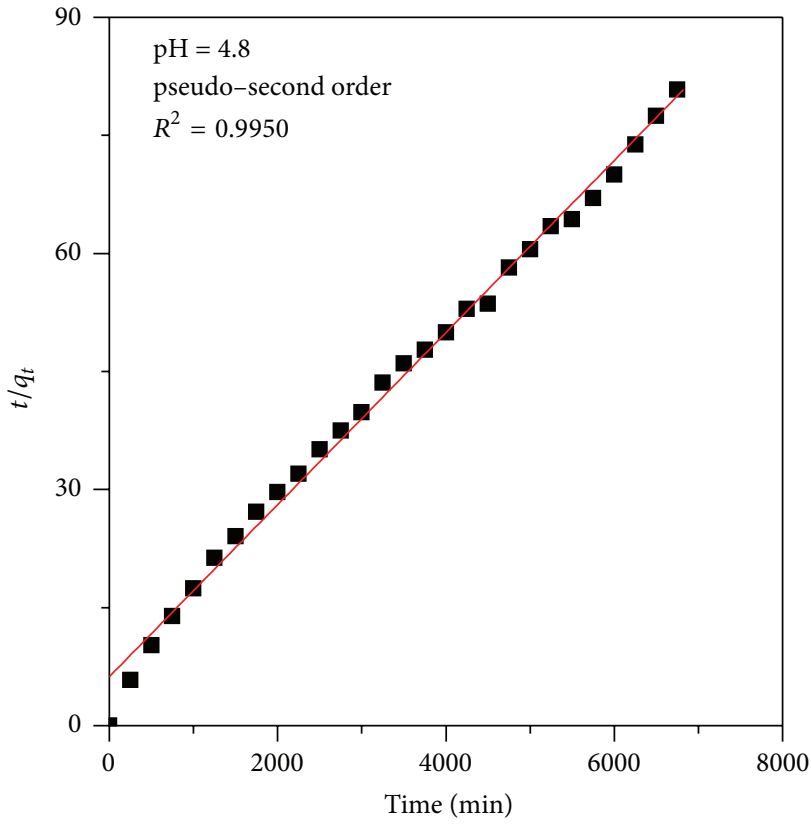

(b)

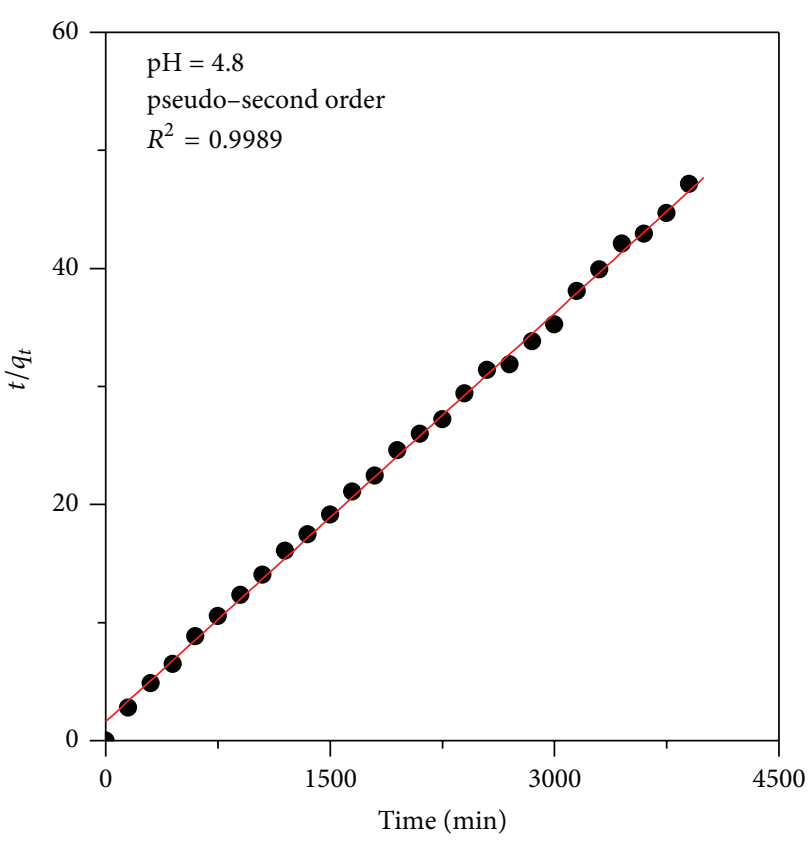

(d)

FIGURE 7: Fitting the data of GA release from FPEGG into different solutions to the pseudo-second-order kinetics for $\mathrm{pH} 7.4$ (a) and $\mathrm{pH} 4.8$ (b) and fitting data of GA released from FPVAG into different solutions to the pseudo-second-order kinetics for $\mathrm{pH} 7.4$ (c) and $\mathrm{pH} 4.8$ (d).

\section{Conclusion}

The synthesized superparamagnetic iron oxide nanoparticles coated with polyethylene glycol-gallic acid and polyvinyl alcohol-gallic acid can be prepared by the coprecipitation method. Iron oxide nanoparticles have the mean size of $9 \mathrm{~nm}$, compared to $31 \mathrm{~nm}$ and $35 \mathrm{~nm}$ for FPEGG and FPVAG nanocomposites. The coating process in both nanocomposites was found to improve the thermal stability of the two resulting nanocomposites compared to their uncoated counterparts. Although the release of the gallic acid from the two nanocomposites (FPEGG and FPVAG) was found to be of controlled manner through an anion exchange process, from the results it was found that the release profiles of GA 


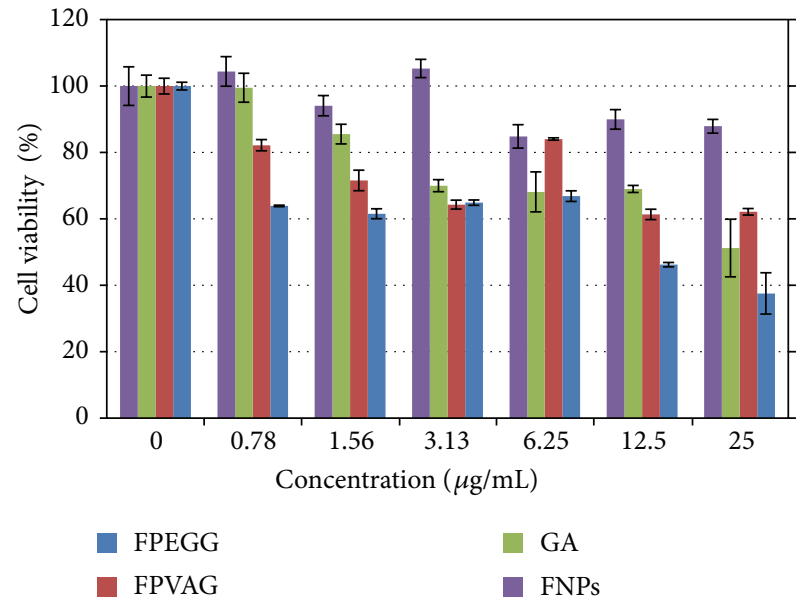

(a)

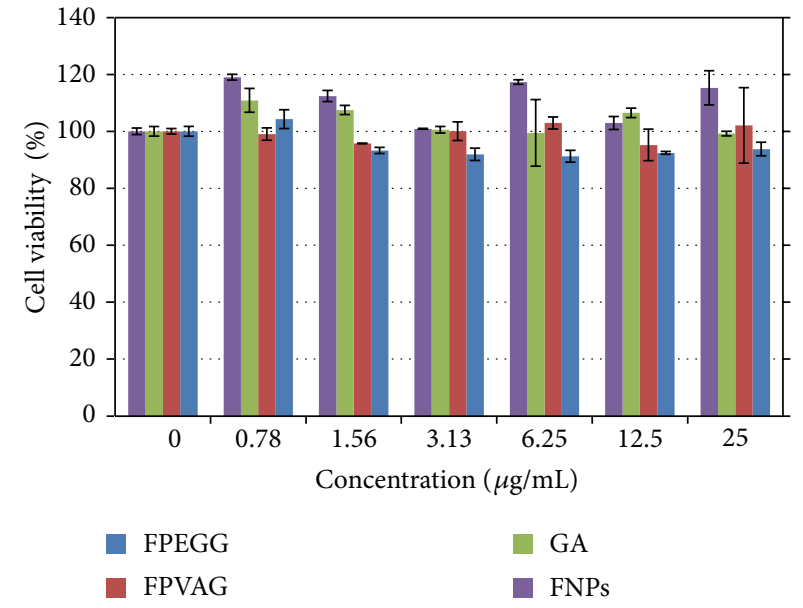

(b)

FIGURE 8: Cell viability assays of (a) MCF-7 cell lines and (b) MRC-5 cells and anticancer activity of FNPs, GA, FPEGG, and FPVAG nanocomposites, respectively, after 72 hours of treatment. FNPs: iron oxide nanoparticles; GA: pure gallic acid; FPEGG: iron oxide coated with polyethylene glycol and gallic acid; FPVAG: iron oxide coated with polyvinyl alcohol and gallic acid.

from FPEGG were more sustained compared to the one from FPVAG nanocomposite. In vitro bioassay study showed that the FPEGG nanocomposite demonstrated higher anticancer effect on the breast cancer cell lines in almost all concentrations tested compared to FPVAG nanocomposite.

\section{Conflict of Interests}

The authors declare that there is no conflict of interests regarding the publication of this paper.

\section{Acknowledgment}

Funding for this research was provided by the Ministry of Science, Technology and Innovation of Malaysia (MOSTI) under the National Nanotechnology Initiative, NND/NA/ (1)/TD11- 010 (Vot no. 5489100).

\section{References}

[1] J. W. M. Bulte and D. L. Kraitchman, "Iron oxide MR contrast agents for molecular and cellular imaging," $N M R$ in Biomedicine, vol. 17, no. 7, pp. 484-499, 2004.

[2] M. Arruebo, R. Fernández-Pacheco, M. R. Ibarra, and J. Santamaría, "Magnetic nanoparticles for drug delivery," Nano Today, vol. 2, no. 3, pp. 22-32, 2007.

[3] J. Chomoucka, J. Drbohlavova, D. Huska, V. Adam, R. Kizek, and J. Hubalek, "Magnetic nanoparticles and targeted drug delivering," Pharmacological Research, vol. 62, no. 2, pp. 144$149,2010$.

[4] M. Y. Ghotbi and M. Z. Bin Hussein, "Controlled release study of an anti-carcinogenic agent, gallate from the surface of magnetite nanoparticles," Journal of Physics and Chemistry of Solids, vol. 73, no. 7, pp. 936-942, 2012.

[5] C. Plank, U. Schillinger, F. Scherer et al., “The magnetofection method: using magnetic force to enhance gene delivery," Biological Chemistry, vol. 384, no. 5, pp. 737-747, 2003.
[6] J. Lee, T. Isobe, and M. Senna, "Preparation of ultrafine $\mathrm{Fe}_{3} \mathrm{O}_{4}$ particles by precipitation in the presence of PVA at high $\mathrm{pH}$," Journal of Colloid and Interface Science, vol. 177, no. 2, pp. 490494, 1996.

[7] T. Sato, T. Iijima, M. Seki, and N. Inagaki, "Magnetic properties of ultrafine ferrite particles," Journal of Magnetism and Magnetic Materials, vol. 65, no. 2-3, pp. 252-256, 1987.

[8] N. A. Ochekpe, P. O. Olorunfemi, and N. C. Ngwuluka, "Nanotechnology and drug delivery part 2: nanostructures for drug delivery," Tropical Journal of Pharmaceutical Research, vol. 8, no. 3, pp. 275-287, 2009.

[9] M. Mahmoudi, A. Simchi, M. Imani, and U. O. Hafeli, "Superparamagnetic iron oxide nanoparticles with rigid cross-linked polyethylene glycol fumarate coating for application in imaging and drug delivery," Journal of Physical Chemistry C, vol. 113, no. 19, pp. 8124-8131, 2009.

[10] A. J. Cole, A. E. David, J. Wang, C. J. Galbán, H. L. Hill, and V. C. Yang, "Polyethylene glycol modified, cross-linked starchcoated iron oxide nanoparticles for enhanced magnetic tumor targeting," Biomaterials, vol. 32, no. 8, pp. 2183-2193, 2011.

[11] M. Mahmoudi, A. Simchi, M. Imani, A. S. Milani, and P. Stroeve, "Optimal design and characterization of superparamagnetic iron oxide nanoparticles coated with polyvinyl alcohol for targeted delivery and imaging," Journal of Physical Chemistry B, vol. 112, no. 46, pp. 14470-14481, 2008.

[12] M. Mahmoudi, A. Simchi, and M. Imani, "Cytotoxicity of uncoated and polyvinyl alcohol coated superparamagnetic iron oxide nanoparticles," Journal of Physical Chemistry C, vol. 113, no. 22, pp. 9573-9580, 2009.

[13] K. G. Paul, T. B. Frigo, J. Y. Groman, and E. V. Groman, "Synthesis of ultrasmall superparamagnetic iron oxides using reduced polysaccharides," Bioconjugate Chemistry, vol. 15, no. 2, pp. 394-401, 2004.

[14] S. K. Sahoo and V. Labhasetwar, "Nanotech approaches to drug delivery and imaging," Drug Discovery Today, vol. 8, no. 24, pp. 1112-1120, 2003.

[15] A. Chanwitheesuk, A. Teerawutgulrag, J. D. Kilburn, and N. Rakariyatham, "Antimicrobial gallic acid from Caesalpinia 
mimosoides Lamk," Food Chemistry, vol. 100, no. 3, pp. 10441048, 2007.

[16] M. Yeganeh Ghotbi and M. Z. Bin Hussein, "Gallate-Zn-Allayered double hydroxide as an intercalated compound with new controlled release formulation of anticarcinogenic agent," Journal of Physics and Chemistry of Solids, vol. 71, no. 11, pp. 1565-1570, 2010.

[17] Y. Zuo, H. Chen, and Y. Deng, "Simultaneous determination of catechins, caffeine and gallic acids in green, oolong, black and pu-erh teas using HPLC with a photodiode array detector," Talanta, vol. 57, no. 2, pp. 307-316, 2002.

[18] D. Dorniani, M. Z. B. Hussein, A. U. Kura, S. Fakurazi, A. H. Shaari, and Z. Ahmad, "Preparation of $\mathrm{Fe}_{3} \mathrm{O}_{4}$ magnetic nanoparticles coated with gallic acid for drug delivery," International Journal of Nanomedicine, vol. 7, pp. 5745-5756, 2012.

[19] M. Strlič, T. Radovič, J. Kolar, and B. Pihlar, "Anti- and prooxidative properties of gallic acid in fenton-type systems," Journal of Agricultural and Food Chemistry, vol. 50, no. 22, pp. 6313-6317, 2002.

[20] H. Lee, H. Shao, Y. Huang, and B. Kwak, "Synthesis of MRI contrast agent by coating superparamagnetic iron oxide with chitosan," IEEE Transactions on Magnetics, vol. 41, no. 10, pp. 4102-4104, 2005.

[21] V. R. Sinha, A. K. Singla, S. Wadhawan et al., "Chitosan microspheres as a potential carrier for drugs," International Journal of Pharmaceutics, vol. 274, no. 1-2, pp. 1-33, 2004.

[22] T. Mosmann, "Rapid colorimetric assay for cellular growth and survival: application to proliferation and cytotoxicity assays," Journal of Immunological Methods, vol. 65, no. 1-2, pp. 55-63, 1983.

[23] S.-J. Xia, Z.-M. Ni, Q. Xu, B.-X. Hu, and J. Hu, "Layered double hydroxides as supports for intercalation and sustained release of antihypertensive drugs," Journal of Solid State Chemistry, vol. 181, no. 10, pp. 2610-2619, 2008.

[24] C. Ribeiro, G. G. C. Arizaga, F. Wypych, and M.-R. Sierakowski, "Nanocomposites coated with xyloglucan for drug delivery: in vitro studies," International Journal of Pharmaceutics, vol. 367, no. 1-2, pp. 204-210, 2009.

[25] H. Zhang, K. Zou, S. Guo, and X. Duan, "Nanostructural druginorganic clay composites: structure, thermal property and in vitro release of captopril-intercalated $\mathrm{Mg}$-Al-layered double hydroxides," Journal of Solid State Chemistry, vol. 179, no. 6, pp. 1792-1801, 2006.

[26] D. Dorniani, M. Z. bin Hussein, A. U. Kura, S. Fakurazi, A. H. Shaari, and Z. Ahmad, "Preparation and characterization of 6-mercaptopurine-coated magnetite nanoparticles as a drug delivery system," Drug Design, Development and Therapy, vol. 7, pp. 1015-1026, 2013.

[27] Y. Hou, Z. Xu, and S. Sun, "Controlled synthesis and chemical conversions of FeO nanoparticles," Angewandte ChemieInternational Edition, vol. 46, no. 33, pp. 6329-6332, 2007.

[28] S. Kayal and R. V. Ramanujan, "Doxorubicin loaded PVA coated iron oxide nanoparticles for targeted drug delivery," Materials Science and Engineering C, vol. 30, no. 3, pp. 484-490, 2010.

[29] M. Sivabalan, V. Gayathri, C. Kiruthika, and B. Madhan, "Formulation and evaluation of biodegradable polyphenolic 30 microspheres for cancer," International Journal of Pharmacy and Technology, vol. 4, no. 2, pp. 4493-4505, 2012.

[30] C. Sun, R. Sze, and M. Zhang, "Folic acid-PEG conjugated superparamagnetic nanoparticles for targeted cellular uptake and detection by MRI," Journal of Biomedical Materials Research $A$, vol. 78, no. 3, pp. 550-557, 2006.
[31] A. Zhu, L. Yuan, and T. Liao, "Suspension of $\mathrm{Fe}_{3} \mathrm{O}_{4}$ nanoparticles stabilized by chitosan and o-carboxymethylchitosan," International Journal of Pharmaceutics, vol. 350, no. 1-2, pp. 361368, 2008.

[32] G. Dodi, D. Hritcu, G. Lisa, and M. I. Popa, "Core-shell magnetic chitosan particles functionalized by grafting: synthesis and characterization," Chemical Engineering Journal, vol. 203, pp. 130-141, 2012.

[33] J. Feng, J. Mao, X. Wen, and M. Tu, "Ultrasonic-assisted in situ synthesis and characterization of superparamagnetic $\mathrm{Fe}_{3} \mathrm{O}_{4}$ nanoparticles," Journal of Alloys and Compounds, vol. 509, no. 37, pp. 9093-9097, 2011.

[34] S.-J. Cho, B. R. Jarrett, A. Y. Louie, and S. M. Kauzlarich, "Goldcoated iron nanoparticles: a novel magnetic resonance agent for T 1 and T2 weighted imaging," Nanotechnology, vol. 17, no. 3, pp. 640-644, 2006.

[35] J. Mürbe, A. Rechtenbach, and J. Töpfer, "Synthesis and physical characterization of magnetite nanoparticles for biomedical applications," Materials Chemistry and Physics, vol. 110, no. 2-3, pp. 426-433, 2008.

[36] A. Debrassi, A. F. Corrêa, T. Baccarin et al., "Removal of cationic dyes from aqueous solutions using N-benzylO-carboxymethylchitosan magnetic nanoparticles," Chemical Engineering Journal, vol. 183, pp. 284-293, 2012.

[37] X. Y. Qin, X. J. Wu, and L. F. Cheng, "Exothermal and endothermal phenomena in nanocrystalline aluminum," Nanostructured Materials, vol. 2, no. 1, pp. 99-108, 1993.

[38] S. Rana, A. Gallo, R. S. Srivastava, and R. D. K. Misra, "On the suitability of nanocrystalline ferrites as a magnetic carrier for drug delivery: functionalization, conjugation and drug release kinetics," Acta Biomaterialia, vol. 3, no. 2, pp. 233-242, 2007.

[39] P. Tartaj, M. P. Morales, T. González-Carreño, S. VeintemillasVerdaguer, and C. J. Serna, "Advances in magnetic nanoparticles for biotechnology applications," Journal of Magnetism and Magnetic Materials, vol. 290-291, pp. 28-34, 2005.

[40] Y. Ge, Y. Zhang, J. Xia et al., "Effect of surface charge and agglomerate degree of magnetic iron oxide nanoparticles on $\mathrm{KB}$ cellular uptake in vitro," Colloids and Surfaces B, vol. 73, no. 2, pp. 294-301, 2009.

[41] J. B. Qu, H. H. Shao, G. L. Jing, and F. Huang, "PEG-chitosancoated iron oxide nanoparticles with high saturated magnetization as carriers of 10-hydroxycamptothecin: preparation, characterization and cytotoxicity studies," Colloids and Surfaces $B$, vol. 102, pp. 37-44, 2013.

[42] S. H. Hussein-Al-Ali, M. Al-Qubaisi, M. Z. Hussein, M. Ismail, Z. Zainal, and M. N. Hakim, "In vitro inhibition of histamine release behavior of cetirizine intercalated into $\mathrm{Zn} / \mathrm{Al}$ and $\mathrm{Mg} / \mathrm{Al}$-layered double hydroxides," International Journal of Molecular Sciences, vol. 13, pp. 5899-5916, 2012.

[43] L. Dong, L. Yan, W.-G. Hou, and S.-J. Liu, "Synthesis and release behavior of composites of camptothecin and layered double hydroxide," Journal of Solid State Chemistry, vol. 183, no. 8, pp. 1811-1816, 2010.

[44] Y.-S. Ho and A. E. Ofomaja, "Pseudo-second-order model for lead ion sorption from aqueous solutions onto palm kernel fiber," Journal of Hazardous Materials, vol. 129, no. 1-3, pp. 137142, 2006.

[45] K. Yin Win and S.-S. Feng, "Effects of particle size and surface coating on cellular uptake of polymeric nanoparticles for oral delivery of anticancer drugs," Biomaterials, vol. 26, no. 15, pp. 2713-2722, 2005. 

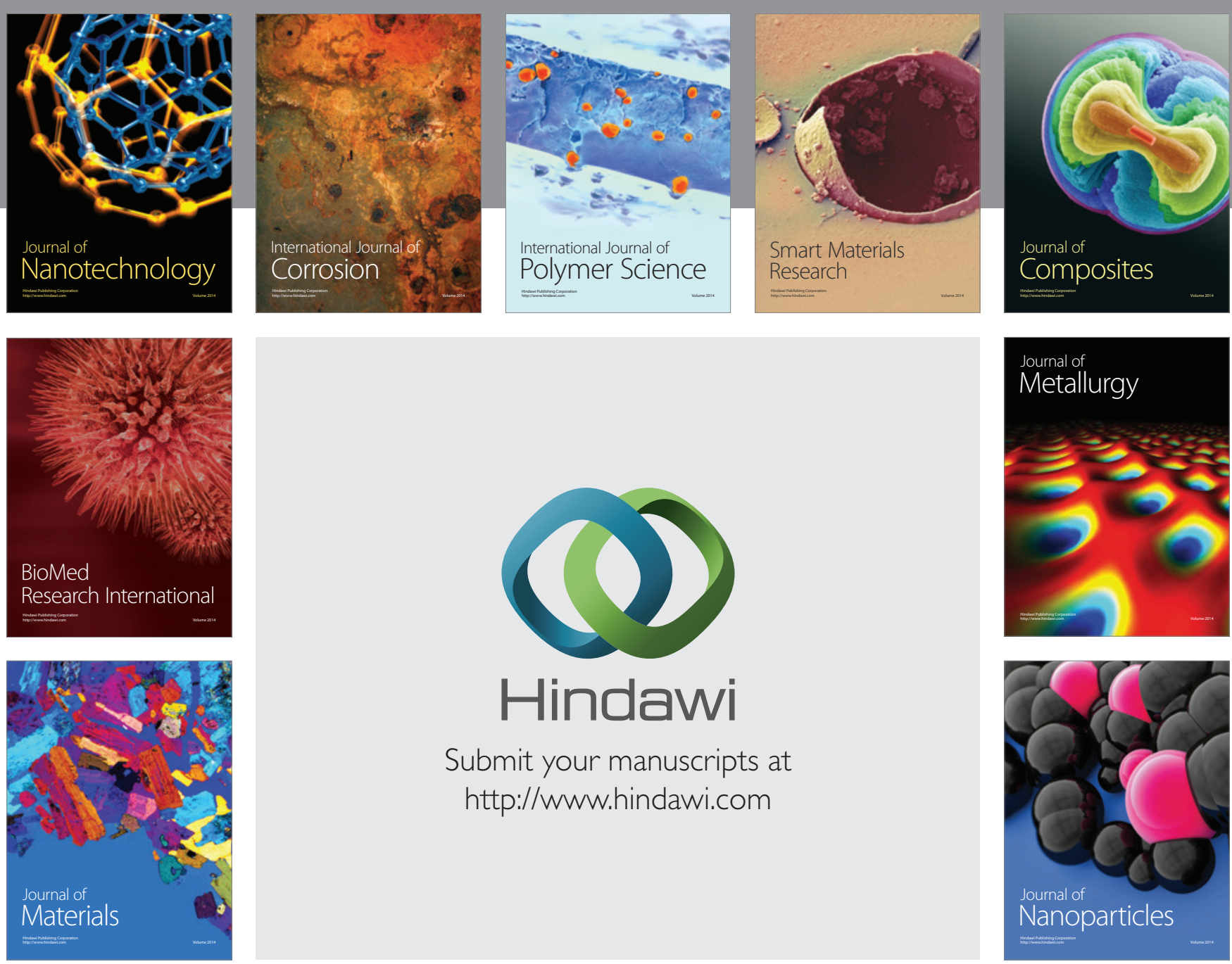

Submit your manuscripts at http://www.hindawi.com
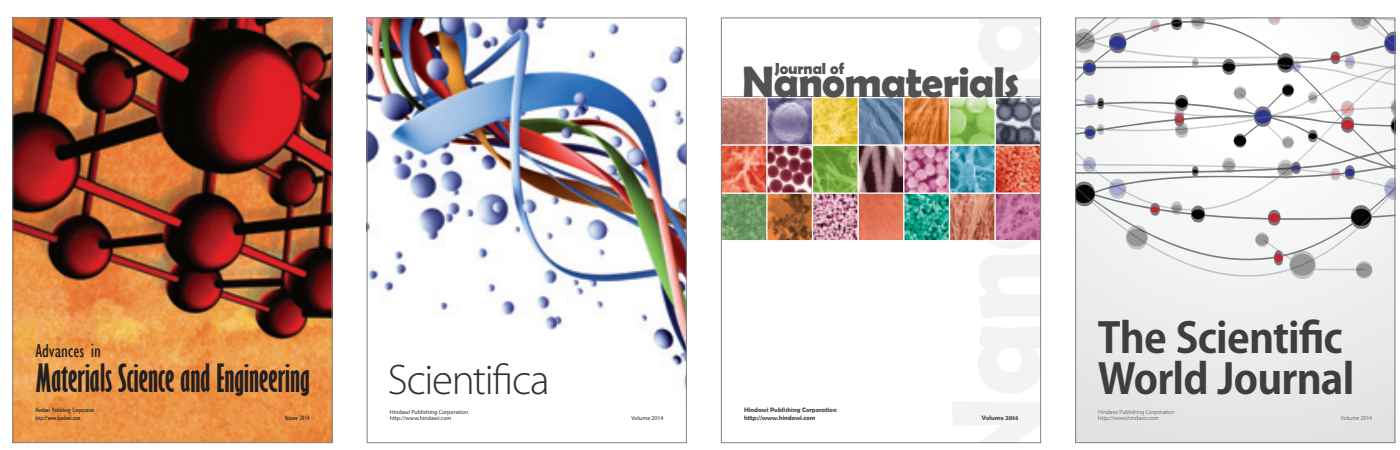

\section{The Scientific World Journal}
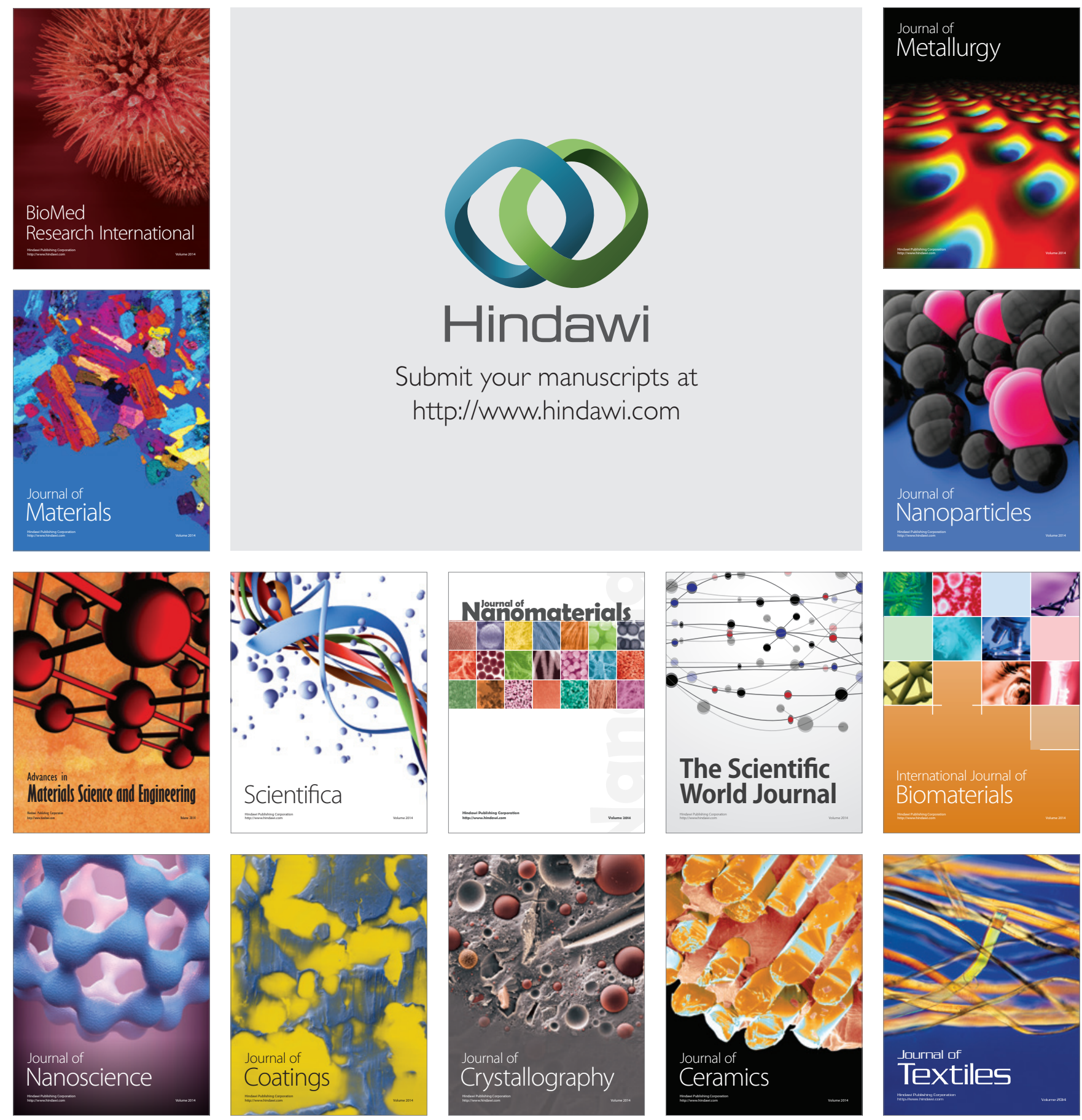